\title{
Identification of Patient Profiles with High Risk of Hospital Re-Admissions for Acute COPD Exacerbations (AECOPD) in France Using a Machine Learning Model
}

This article was published in the following Dove Press journal:

International Journal of Chronic Obstructive Pulmonary Disease

\author{
Arnaud Cavailles' \\ Boris Melloni ${ }^{2}$ \\ Stéphane Motola ${ }^{3}$ \\ Florent Dayde $\mathbb{D}^{3}$ \\ Marie Laurent $\mathbb{1 D}^{3}$ \\ Katell Le Lay ${ }^{4}$ \\ Didier Caumette ${ }^{5}$ \\ Laura Luciani ${ }^{4}$ \\ Pierre Louis Lleu ${ }^{6}$ \\ Geoffrey Berthon ${ }^{7}$ \\ Thomas Flament ${ }^{8}$ \\ 'Service de Pneumologie, Institut du \\ Thorax, CHU de Nantes, Nantes, France; \\ ${ }^{2}$ Service de Pneumologie, $\mathrm{CHU}$ \\ Dupuytren, Limoges, France; ${ }^{3} \mathrm{HEVA}$, \\ Lyon, France; ${ }^{4} \mathrm{HEOR} / \mathrm{RWE}$, Boehringer \\ Ingelheim, Paris, France; ${ }^{5}$ Institutional and \\ Hospital Partnership, Boehringer \\ Ingelheim, Paris, France; ${ }^{6}$ Medical Affairs, \\ Boehringer Ingelheim, Paris, France; \\ ${ }^{7} \mathrm{CHRU}$ Tours, Tours, France; ${ }^{8}$ Service de \\ Pneumologie, CHRU Bretonneau, Tours, \\ France
}

Purpose: To characterise patients with chronic obstructive pulmonary disease (COPD) who are rehospitalised for an acute exacerbation, to estimate the cost of these hospitalisations, to characterise high risk patient sub groups and to identify factors potentially associated with the risk of rehospitalisation.

Patients and Methods: This was a retrospective study using the French National Hospital Discharge Database. All patients aged $\geq 40$ years hospitalised for an acute exacerbation of COPD between 2015 and 2016 were identified and followed for six months. Patients with at least one rehospitalisation for acute exacerbation of COPD constituted the rehospitalisation analysis population. A machine learning model was built to study the factors associated with the risk of rehospitalisation using decision tree analysis. A direct cost analysis was performed from the perspective of national health insurance.

Results: A total of 143,006 eligible patients were hospitalised for an acute exacerbation of COPD (AECOPD) in 2015-2016 (mean age: 74 years; 62.1\% men). 25,090 (18.8\%) were rehospitalised for another exacerbation within six months. In this study, $8.5 \%$ of patients died during or immediately following the index hospitalisation and $10.5 \%$ died during or immediately after rehospitalisation $(p<0.001$ ). The specific cost of these rehospitalisations was $€$ 5304. The overall total cost per patient of all AECOPD-related stays was $€ 9623$, being significantly higher in patients who were rehospitalised $(€ 16,275)$ compared to those who were not $(€ 8208)$. In decision tree analysis, the most important driver of rehospitalisation was hospitalisation in the previous two years (contributing $85 \%$ of the information).

Conclusion: Rehospitalisations for acute exacerbations of COPD carry a high epidemiological and economic burden. Since hospitalisation for an acute exacerbation is the most important determinant of future rehospitalisations, management of COPD needs to focus on interventions aimed at decreasing the rehospitalisation risk of in order to lower the burden of disease.

Keywords: comorbidity, rehospitalisation, decision tree analysis, cost

\section{Introduction}

Chronic obstructive pulmonary disease (COPD) is a persistent, progressive debilitating respiratory condition characterized by persistent respiratory symptoms and airflow limitation. ${ }^{1}$ It is most frequently caused by cigarette smoking. COPD was the fourth leading cause of death worldwide in $2010^{2}$ and is predicted to rise to third place in 2020 . ${ }^{1,3}$ Prevalence of COPD varies between countries, but the number of cases worldwide has
Correspondence: Marie Laurent 186 Avenue Thiers, Lyon 69006, France Tel +33472742560

Email mlaurent@hevaweb.com 
been estimated to be over 350 million. ${ }^{1}$ Estimates of the prevalence of COPD in adults aged forty years or over in France have ranged between $3.2 \%$ and $7.5 \%,{ }^{4-6}$ depending on the definition and sampling methods used. Mortality rates attributable to COPD in France in 2006 were 41/100,000 in men and $17 / 100,000$ in women aged over 45 years. $^{7}$ Management of COPD represents a considerable economic burden, accounting for around $6 \%$ of the total healthcare budget in the European Union ( $€ 39$ billion). ${ }^{1}$ The mean annual direct per capita medical costs of management of COPD in 2011 in France were estimated to be $€ 5516$. $^{8}$

Acute exacerbations of COPD (AECOPD) correspond to transitory worsening of respiratory symptoms which, in severe cases, may require hospitalisation. ${ }^{1}$ Such exacerbations are associated with an increased mortality risk $^{9,10}$ and are an important driver of cost. ${ }^{10}$ The SCOPE study reported that patients with COPD in France experience on average 1.7 AECOPD each year, with this number increasing with disease severity. ${ }^{11}$ Several studies have investigated predictors of AECOPD. For example, in the longitudinal ECLIPSE cohort, the single best predictor of the frequency of exacerbations, and of hospitalisation for AECOPD, was a history of previous exacerbations. ${ }^{12,13}$ Other predictors included lower forced expiratory volume (FEV), a history of gastrooesophageal reflux disorder and elevated lymphocyte count. ${ }^{12}$ Imaging markers were evaluated in the COPD gene cohort, in which greater lung emphysema and airway wall thickness were associated with AECOPD. ${ }^{14}$ In the SPIROMICS cohort, prior exacerbation history, high COPD Assessment Test (CAT) scores, small airway abnormalities visible on imaging, low interleukin- 15 and elevated interleukin-8 were identified as predictors of consistent exacerbation status. ${ }^{15}$ Elevated fibrinogen was found to be a marker of increased risk of AECOPD and of mortality in a pooled analysis of five clinical studies performed by the COPD Biomarkers Qualification Consortium. ${ }^{16}$

The above studies have generally used multivariate regression analysis to identify factors associated with AECOPD. Another approach would be to use machine learning models such as cluster analysis or decision tree analysis to identify subgroups of patients at high risk for exacerbations. ${ }^{17}$ Such an approach may pave the way for personalised medicine whereby patients are treated in function of their individual risk profiles. ${ }^{18}$ Cluster analysis has been applied to the database of the ECLIPSE cohort to identify patient subgroups with different clinical outcomes and different biomarker profiles. ${ }^{19}$ An Indian study has used decision tree analysis to identify undiagnosed patients hospitalised with symptoms suggestive of COPD. ${ }^{20}$ The present study describes the use of a decision tree analysis to identify factors potentially associated with the risk of rehospitalisation for AECOPD and to characterise potential subgroups of patients at high risk for rehospitalisation.

\section{Methods}

\section{Study Design}

This study was performed at the request of the French Health Authorities (Haute Autorité de Santé) in order to collect information on the cost of hospitalisations associated with the AECOPD documented in the French Hospital medical information database. The study population consisted of all patients hospitalised for an AECOPD between 2015 and 2016. All patients were then followed up for six months. Data extraction and analysis followed the guidelines for use of this database. ${ }^{21}$ A direct cost analysis was performed from the perspective of the French national health insurance.

\section{The French National Hospital Database}

The French National Hospital Discharge Database (PMSI) is an exhaustive medico-administrative hospital discharge database which covers all short time hospitalisations in the public and private sectors involving stays in medical, surgical or obstetric facilities, representing more than $95 \%$ of all day-care and inpatient stays in France ( $\sim 30$ million stays per year). Data from the PMSI are available for epidemiological or pharmaco-economic studies and have been used in numerous government reports and scientific publications on the burden of hospitalisation. ${ }^{22}$

In the PMSI, individual patients can be tracked across multiple hospitalisations through a unique anonymous patient identifier, which is conserved until the patient dies. All hospital stays are documented at the time of final discharge, and given a diagnostic identifier (Diagnosis Related Group; DRG) based on ICD-10 diagnostic codes for the primary diagnosis that led to hospital admission, and any related or associated diagnoses. Each is attributed a fixed, annual national tariff, which is different for public and private establishments, for accounting purposes and used as the basis for hospital costing. The date and duration of the hospital stay, and the hospital departments involved, are documented, as well as the destination of the patient after hospitalisation (eg home or residential care) and where the patient was hospitalised from (eg emergency department or home). The database contains limited socio-demographic information (gender, age, code postcode of residence), and 
data on underlying comorbidities and potential complications of hospitalisation. It includes examinations and procedures undergone during the stay, using a standard coding convention. In-hospital deaths are also documented. The cost of medication delivery is included in the DRG, and information on individual treatments is thus not accessible in the database, with the exception of a limited number of expensive innovative treatments, which are accounted for separately.

\section{Identification of the Study Population}

The full study cohort is composed of all patients aged $\geq 40$ years hospitalised for AECOPD between 1st January 2015 and 31st December 2016 throughout France. These hospitalisations are identified based on the DRG code for the stay using an algorithm validated by the French Institute for Public Health Surveillance (InVS) for the identification of hospitalisations for AECOPD (Figure 1). ${ }^{23}$ Stays lasting less than two days were excluded, unless the patient died in hospital. The first hospital stay for an AECOPD is considered the index hospitalisation. All patients were followed for six months after the index hospitalisations in order to identify any rehospitalisations for AECOPD. These hospitalisations were identified using the same algorithm as for the index hospitalisation (Figure 1). Patients with at least one rehospitalisation for AECOPD during this time made up the rehospitalisation analysis population.

\section{Variables of Interest}

For each patient, the age, gender, and municipality of residence were documented. For the municipality of residence, two sociodemographic indices were determined based on national census data. An Urban/Rural Index (URI) was

\section{$\mathbf{J 4 4 . 0}$
PD $\quad$ COPD with acute infection of airways}

\section{OR}

\begin{tabular}{|c|c|}
\hline PD & J44.1 \\
& COPD with acute non-specified episode \\
\hline
\end{tabular}

\section{OR}

\begin{tabular}{|c|c|}
\hline PD & J96.0 \\
& Acute respiratory failure \\
\hline
\end{tabular}

\section{OR}

\begin{tabular}{|c|c|}
\hline PD & J09-18, J20-22 \\
\hline
\end{tabular}

\section{OR}

\begin{tabular}{|c|c|}
\hline PD & $\begin{array}{c}\mathbf{J 4 4} \\
\text { COPD }\end{array}$ \\
\hline \multicolumn{2}{|c|}{ OR } \\
\hline PD & $\begin{array}{c}\mathbf{J 4 3} \\
\text { Emphysaema }\end{array}$ \\
\hline
\end{tabular}

AND

AND

\begin{tabular}{|c|c|}
\hline AD & J44 COPD \\
\hline & OR \\
\hline AD & J43 Emphysema \\
\hline
\end{tabular}

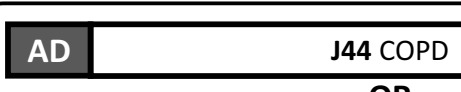

OR

\begin{tabular}{l|r}
\hline AD & J43 Emphysema \\
\hline
\end{tabular}

\begin{tabular}{|l|l|}
\hline AD & J44.0 COPD with acute infection of airways \\
\hline
\end{tabular}

OR

\begin{tabular}{|l|l|}
\hline AD & J44.1 COPD with acute non-specified episode
\end{tabular}

OR

AND

Figure I Algorithm for identifying hospital stays for acute exacerbations of COPD. The corresponding ICD-I0 codes are indicated in bold. This algorithm was developed by the French National Health Surveillance Institute (InVS); data apdated from Fuhrman and Delmas. ${ }^{23}$

Abbreviations: PD, primary diagnosis; AD, associated diagnosis. 
determined in the basis of the total number of inhabitants and divided into four classes: rural $(<2000)$, semi-rural (2000-9999), semi-urban (10,000-99,999), and urban $(\geq 100,000)$. The Social Deprivation Index $(\mathrm{SDI})^{24}$ is a composite measure taking into account the unemployment rate, median household income, the percentage of high school graduates in the adult population, and the percentage of blue-collar workers in the active population. ${ }^{24}$ This SDI has been previously validated in France as a tool for evaluating socioeconomic disparities in health at the level of the municipality. ${ }^{24}$ Municipalities are divided into quartiles corresponding to the most deprived, deprived, privileged, and most privileged communities.

With respect to medical variables, the number of previous hospitalisations for AECOPD in the two years before the index hospitalisation was also determined for each patient. Comorbidities were identified from the DRG notified on the discharge summary for any hospital stay within a year before and a year after the index hospitalisation. The following comorbidities were documented specifically: cardiovascular diseases, nutritional disorders, diabetes, obesity, sleep disorders, anxiety, depression, lung and bladder cancer or musculoskeletal disorders.

The origin of the patient at admission and destination at discharge were identified. In the PMSI database, these are classified as "emergency department", "other medical facilities" or "undefined". "Undefined" usually refers to the patient's home. Any transfers to an intensive care unit were identified. Any in-hospital deaths occurring during the followup period were documented. The time between the index date and the first AECOPD rehospitalisation was described. Inhospital respiratory rehabilitation (RR) sessions or respiratory functional explorations (RFE) within thirty days following index hospitalisation were documented.

\section{Cost Analysis}

Direct costs correspond to the amount reimbursed by the French national health insurance to the hospital and are attributed using official French national tariffs applicable from 2015 to 2017, expressed in 2018 euros. A standard national tariff was applied to each hospital stay based on the DRG code attributed in the PMSI database. These standard tariffs include medical and related procedures, nursing care, treatments (except specific expensive drugs), food and accommodation, and related investment costs for hospitalised patients. Additional costs per day of hospitalisation in an intensive care unit were added to the DRG tariff when appropriate. For private hospitals, where physicians are reimbursed on a fee-for-service basis, physician fees were identified from the French observatory of real-world spending on healthcare (ENCC) and added to the private DRG tariff. Expensive drugs and implants were costed using the retail price listed in the public FICHCOMP database and using the official tariff for the private FICHCOMP database.

Two costs were measured for the six months following the index hospitalisation, namely the specific cost of the first AECOPD rehospitalisation and the overall total cost of all COPD-related stays. The latter cost includes the cost of the index AECOPD hospital stay, the cost of any RFE or RR within thirty days after the index stay, the cost of any AECOPD rehospitalisation, as well as any hospital stay considered by the study steering committee as being related to COPD.

\section{Descriptive Statistical Analyses}

No pre-defined hypotheses were tested, and the statistical analyses are principally exploratory and descriptive. Continuous variables are presented as mean, standard deviation (SD), median, quartiles. Categorical variables are presented as frequency tables. Continuous variables were compared using Student's $t$-test or the Wilcoxon test as appropriate, and categorical variables compared with the $\chi^{2}$ test or Fisher's exact test as appropriate. The association between the proportion of patients who were rehospitalised on the one hand and the number of previous hospitalisations for AECOPD on the other was evaluated by linear regression analysis and quantified as a Pearson correlation coefficient.

\section{Decision Tree Analysis}

A machine learning model using decision tree analysis was built on Python software to study the factors associated with the risk of having at least one rehospitalisation for AECOPD within six months of the index hospitalisation using a binary splitting decision tree algorithm. ${ }^{17,25}$ The resulting tree is represented as a "sunburst plot".

The model was initially constructed on a random sample of $80 \%$ of the study cohort (the training set). The model was built iteratively, starting with the full training set (the root, the centre of the sunburst) and first searched for the most discriminating variable to divide the cohort into two subgroups (the branches, the innermost circle) which segregated the target variable (presence or absence of at least an AECOPD rehospitalisation) as much as possible. The potential discriminating variables entered into the algorithm are listed in Table 1. In this model, comorbidities were identified from the DRG notified on the discharge summary for any hospital stay in the year preceding, 
or at the time of, the index hospitalisation. The quality of segregation was estimated by the Gini impurity statistic. A variable was considered to be the most discriminating when this statistic was highest. In each following round, each branch was split into two further sub-branches using the same procedure (on the sunburst plot, each segment of the circle is divided in two sub-segments). Further sub-branches were developed until one of three criteria were met, namely when the resulting subgroup corresponded to $<1 \%$ of the original cohort, when the gain in Gini impurity statistic was minimal $\left(<10^{-7}\right)$ or when six levels of division from the root had been reached.

In a second step, the model's performance was then tested on the remaining unseen $20 \%$ of the cohort (the validation set) to validate the model and to control for overfitting. The model was considered validated if the decision tree hierarchy in the validation set matched that in the training set and if the performance (accuracy, recall, precision and $\mathrm{fl}$ score) in the two data sets were comparable.

Finally, if the model was considered validated in the validation set, then the model was frozen. The two datasets were combined and the model reiterated in the complete dataset in order to generate the final results. For each relevant profile, relative risks and $95 \%$ bootstrap confidential interval were computed.

\section{Ethics}

The study was conducted in accordance with relevant international and French regulatory requirements. Ethics committee approval was not required. Use of the PMSIMCO database was approved by the French national data protection agency (CNIL; annual authorization \#1419102 v7-2015-111111-56-18/order M14N056 and M14L056).

\section{Results}

\section{Characteristics of the Study Cohort}

Overall, 143,006 patients aged $\geq 40$ years were hospitalised for AECOPD in 2015-2016. The characteristics of the cohort are presented in Table 2. The mean age was 74 years and $62.1 \%$ were male. These patients most frequently lived in rural areas and socially-deprived municipalities. Over half the COPD cohort had comorbid cardiovascular disease. The other comorbidities identified are described in Table 2. A previous hospitalisation for AECOPD over the two years preceding the index hospitalisation was documented for $16.2 \%$ of the cohort.

\section{Index Hospitalisation of the Study Cohort}

The average duration of the index hospitalisation was 10.9 days (Table 2). The majority of patients (70.7\%) were admitted from an emergency department. At discharge, the majority $(83.0 \%)$ went back home. During the index stay, $19.9 \%$ of patients went to an intensive care unit. Over the thirty days following discharge, $3.6 \%$ of patients who did not die during their index hospitalisation underwent inhospital RR and 13.7\% underwent in-hospital RFE.

\section{Rehospitalisation for an AECOPD}

Of the 133,628 patients in the cohort alive at the end of the index stay, $76,471(57.2 \%)$ were rehospitalised within six

Table I Discriminating Variables Entered into the Decision Tree Model

\begin{tabular}{|c|c|c|}
\hline Patient-Related Variables & COPD-Related Variables & Hospitalisation-Related Variables \\
\hline Age (Continuous variable) & AECOPD in previous 2 years (Continuous variable) & Length of stay (Continuous variable) \\
\hline Gender (Binary variable) & $\begin{array}{l}\text { Comorbidities, documented over a period of } 12 \\
\text { months prior to the index hospitalisation and during } \\
\text { the index hospitalisation } \\
\left(I^{\text {st }} \text { iteration: continuous variable) }\right. \\
\text { ( } 2^{\text {nd }} \text { iteration: dummy variable - one binary variable } \\
\text { for each comorbidity) }\end{array}$ & Origin at admission (Categorical variable) \\
\hline $\begin{array}{l}\text { Urban-rural index (Binary variable: rural } \\
\text { or semi-rural vs urban or semi-urban) }\end{array}$ & & Destination at discharge (Categorical variable) \\
\hline \multirow[t]{3}{*}{$\begin{array}{l}\text { Social deprivation index (Binary variable: } \\
\text { most deprived or deprived vs most } \\
\text { privileged or privileged) }\end{array}$} & & Public or private hospital (Binary variable) \\
\hline & & Medical or surgical ward (Binary variable) \\
\hline & & Stay in an intensive care unit (Binary variable) \\
\hline
\end{tabular}

Abbreviations: AECOPD, acute exacerbation of COPD; COPD, chronic obstructive pulmonary disease. 
Table 2 Characteristics of the Study Cohort: Sociodemographic Features, Comorbidities and Hospitalisation

\begin{tabular}{|c|c|c|c|c|}
\hline \multicolumn{2}{|c|}{ Patient Characteristics at Index Hospitalisation } & \multirow{2}{*}{$\begin{array}{l}\text { Study Cohort } \\
(N=143,006)\end{array}$} & \multirow{2}{*}{$\begin{array}{l}\text { Rehospitalisation } \\
(N=\mathbf{2 5}, 090)\end{array}$} & \multirow{2}{*}{$\begin{array}{l}\text { No } \\
\text { Rehospitalisation } \\
(N=108,538)\end{array}$} \\
\hline & & & & \\
\hline \multirow[t]{2}{*}{ Age } & Mean \pm SD & $73.9 \pm 12.2$ & $74.1 \pm 11.5$ & $73.4 \pm 12.3$ \\
\hline & Median [IQR] & $75[65-84]$ & $75[66-83]$ & 75 [64-83] \\
\hline \multirow[t]{2}{*}{ Gender } & Men & $88,820(62.1 \%)$ & $16,383(65.3 \%)$ & $66,158(61,0 \%)$ \\
\hline & Women & $54,186(37.9 \%)$ & $8707(34.7 \%)$ & $42,380(39.0 \%)$ \\
\hline \multirow[t]{5}{*}{ Social deprivation index } & Most deprived & $43,775(30.5 \%)$ & $8126(32.4 \%)$ & $32,778(30.2 \%)$ \\
\hline & Deprived & $37,690(26.5 \%)$ & $6470(25.8 \%)$ & 28,771 (26.5\%) \\
\hline & Privileged & $29,374(20.6 \%)$ & $5072(20.2 \%)$ & $22,323(20.6 \%)$ \\
\hline & Most privileged & $29,630(20.7 \%)$ & 4992 (19.9\%) & 22,681 (20.9\%) \\
\hline & Undefined & $2537(1.7 \%)$ & $430(1.7 \%)$ & $1985(1.8 \%)$ \\
\hline \multirow[t]{5}{*}{ Urban/Rural index } & Rural & $52,025(36.5 \%)$ & 8976 (35.8\%) & $39,452(36.3 \%)$ \\
\hline & Semi-rural & $37,84 \mid(26.4 \%)$ & $6616(26.4 \%)$ & $28,696(26.4 \%)$ \\
\hline & Semi-urban & 39,362 (27.4\%) & $6996(27.9 \%)$ & 29,914 (27.6\%) \\
\hline & Urban & 12,963 (9.2\%) & $2389(9.5 \%)$ & $9813(9.0 \%)$ \\
\hline & Undefined & $815(0.6 \%)$ & $113(0.5 \%)$ & $663(0.6 \%)$ \\
\hline \multirow[t]{9}{*}{ Comorbidities } & Cardiovascular disease & 78,717 (55.0\%) & $16,314(65.0 \%)$ & $55,987(51.6 \%)$ \\
\hline & Nutritional disorders & 62,166 (43.5\%) & 14,076 (56.1\%) & $43,448(40.0 \%)$ \\
\hline & Diabetes & 33,667 (23.5\%) & $6273(25.0 \%)$ & $25,311(23.3 \%)$ \\
\hline & Obesity & 27,118 (19.0\%) & 5201 (20.1\%) & $20,610(19.0 \%)$ \\
\hline & Sleep disturbances & 21,743 (15.2\%) & $4660(18.6 \%)$ & $|6,08|(\mid 4.8 \%)$ \\
\hline & Anxiety & $15,720(11.0 \%)$ & 4390 (17.5\%) & 10,556 (9.7\%) \\
\hline & Depression & $|4,66|(10.3 \%)$ & 3572 (14.2\%) & $10,438(9.6 \%)$ \\
\hline & Lung/bladder cancer & $|I, 25|(7.9 \%)$ & 2274 (9.1\%) & 7914 (7.3\%) \\
\hline & $\begin{array}{l}\text { Musculoskeletal } \\
\text { disorders }\end{array}$ & $6256(4.4 \%)$ & $159 \mid(6.3 \%)$ & 4301 (4.0\%) \\
\hline \multirow{5}{*}{$\begin{array}{l}\text { Number of AECOPD hospitalisations before } \\
\text { inclusion }\end{array}$} & 0 & I I 9,776 (83.8\%) & 17,499 (69.7\%) & $94,523(87.1 \%)$ \\
\hline & I & I4,773 (10.3\%) & 3946 (15.7\%) & 9792 (9.0\%) \\
\hline & 2 & 4509 (3.2\%) & $1639(6.5 \%)$ & $2546(2.3 \%)$ \\
\hline & 3 or more & $3948(2.8 \%)$ & $2006(8.0 \%)$ & $1677(1.5 \%)$ \\
\hline & I or more & $23,230(16.2 \%)$ & $7590(30.3 \%)$ & 14,015 (12.9\%) \\
\hline \multicolumn{2}{|l|}{ Characteristics of hospital stay } & Index stay & Rehospitalisation & \\
\hline \multirow[t]{2}{*}{ Length of stay (days) } & Mean \pm SD & $10.9 \pm 10.2$ & $11.3 \pm 9.3$ & - \\
\hline & Median [IQR] & $8[5-13]$ & $9[6-14]$ & - \\
\hline Passage in ICU unit & & 28,486 (19.9\%) & $508 \mathrm{I}(20.3 \%)$ & - \\
\hline \multirow[t]{3}{*}{ Origin at admission } & Emergency & I0I,I 25 (70.7\%) & $17,049(68.0 \%)$ & - \\
\hline & Others health facilities & II,529 (8.1\%) & $2385(9.5 \%)$ & - \\
\hline & Undefined (mostly "home") & $30,352(21.2 \%)$ & $5656(22.5 \%)$ & - \\
\hline \multirow[t]{7}{*}{ Destination at discharge } & Intensive care & $12,425(8.7 \%)$ & $2632(10.5 \%)$ & - \\
\hline & Acute care & $6227(4.4 \%)$ & $1097(4.4 \%)$ & - \\
\hline & Medico-social structure & $3664(2.6 \%)$ & $687(2.7 \%)$ & - \\
\hline & Long-term care & $94 \mathrm{I}(0.7 \%)$ & $204(0.8 \%)$ & - \\
\hline & Psychology & $605(0.4 \%)$ & $99(0.4 \%)$ & - \\
\hline & Home hospitalisation & $378(0.3 \%)$ & $102(0.4 \%)$ & - \\
\hline & Undefined (mostly "home") & II $8,766(83.0 \%)$ & $20,269(80.8 \%)$ & - \\
\hline
\end{tabular}

(Continued) 
Table 2 (Continued).

\begin{tabular}{|c|c|c|c|c|}
\hline \multicolumn{2}{|l|}{ Characteristics of hospital stay } & \multirow{2}{*}{$\begin{array}{l}\text { Index stay } \\
9378(6.6 \%) \\
|2,04|(8.4 \%)\end{array}$} & \multirow{2}{*}{$\begin{array}{l}\text { Rehospitalisation } \\
184 \mid(7.3 \%) \\
2462(9.8 \%)\end{array}$} & \multirow{2}{*}{-} \\
\hline In-hospital death & $\begin{array}{l}\text { During the stay } \\
\text { Within } 30 \text { days of discharge (stay } \\
\text { included) }\end{array}$ & & & \\
\hline \multicolumn{2}{|l|}{ Other follow-up variables } & Study cohort & Rehospitalisation & No Rehospitalisation \\
\hline $\begin{array}{l}\text { Time between inclusion and the Ist } \\
\text { rehospitalisation }\end{array}$ & $\begin{array}{l}\text { Mean } \pm \text { SD (Months) } \\
\text { Median [IQR] }\end{array}$ & - & $\begin{array}{l}2.2 \pm 1.7 \\
1.8[0.6-3.5]\end{array}$ & - \\
\hline \multicolumn{2}{|c|}{$\begin{array}{l}\text { RR performed at hospital (within } 30 \text { days after inclusion)* } \\
\text { RFE performed at hospital (within } 30 \text { days after inclusion)* }\end{array}$} & $\begin{array}{l}4814(3.6 \%) \\
18,249(13.7 \%)\end{array}$ & $\begin{array}{l}1224(4.9 \%) \\
6535(26.0 \%)\end{array}$ & $\begin{array}{l}3590(3.3 \%) \\
11,713(10.8 \%)\end{array}$ \\
\hline Number of AECOPD rehospitalisation* & $\begin{array}{l}1 \\
2 \\
3 \text { or more }\end{array}$ & $\begin{array}{l}- \\
- \\
-\end{array}$ & $\begin{array}{l}18,889(14.1 \%) \\
4457(3.3 \%) \\
1744(1.3 \%)\end{array}$ & $\begin{array}{l}- \\
- \\
-\end{array}$ \\
\hline
\end{tabular}

Note: *For these variables, percentages are calculated with respect to 133, 628 patients who did not die during the index hospitalisation and were discharged.

Abbreviations: AECOPD, acute exacerbation of COPD; COPD, chronic obstructive pulmonary disease; ICU, intensive care unit; RR, Respiratory Rehabilitation; RFE, Respiratory functional explorations.

months of the index hospitalisation, regardless of the reason, and 25,090 (18.8\%) were hospitalised at least once for another AECOPD (Figure 2). These patients were most frequently rehospitalised for an AECOPD only once during the six months of follow-up ( $\mathrm{N}=18,889 ; 14.1 \%)$; 4457 (3.3\%) patients were rehospitalised twice and 1744 $(1.3 \%)$ three or more times (Table 2$)$. On average, the first rehospitalisation for AECOPD occurred $2.2 \pm 1.7$ months after initial discharge from the index hospitalisation. The average duration of the rehospitalisation was 11.3 days (Table 2).

The characteristics of the subgroup rehospitalised for an AECOPD are presented in Table 2. Compared to patients who were not rehospitalised, the patients were more frequently male, more frequently came from a socially deprived municipality, had more comorbid diseases, were more likely to have been hospitalised for an AECOPD in the previous two years, and more frequently underwent RR or RFE (Table 2). All the characteristics presented in Table 2 differ significantly between the two groups $\left(p<0.001 ; \chi^{2}\right.$ test), except for the Urban/Rural Index ( $p=0.05 ; \chi^{2}$ test). The proportion of patients rehospitalised for an AECOPD was highly correlated $\left(\mathrm{R}^{2}=0.994\right)$ with the number of previous hospitalisations for AECOPD in the two years before the index hospitalisation (Figure 3).

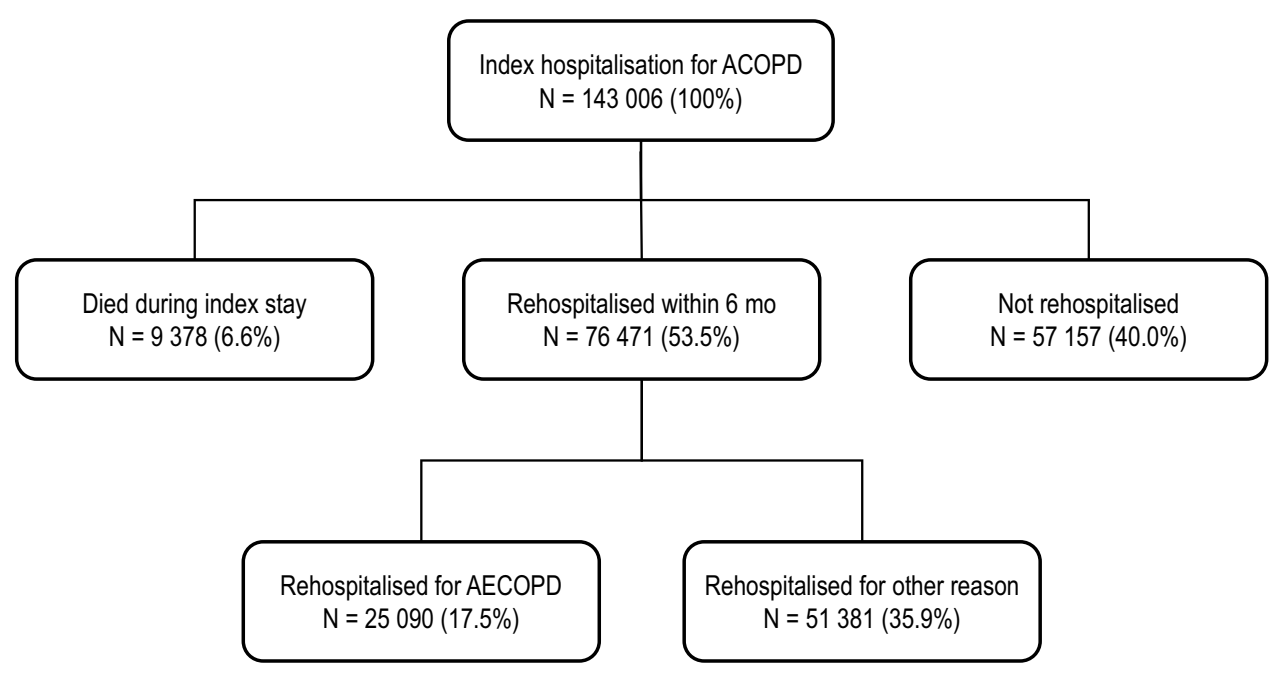

Figure 2 Distribution of hospitalisations. Percentages are calculated with respect to the 143,006 patients in the full study cohort. Abbreviation: AECOPD, acute exacerbations of chronic obstructive pulmonary disease. 


\section{In-Hospital Mortality}

Overall, 9378 patients $(6.6 \%)$ died during the index hospitalisation and a further 2663 (1.9\%) died within 30 days of admission. During the first rehospitalisation, 1841 patients (7.3\%) died and a further 621 (2.5\%) during the following thirty days. These two proportions were significantly higher ( $\mathrm{p}<0.001 ; \chi^{2}$ test) than the proportions of patients who died during the index hospitalisation (or within 30 days of admission).

\section{Costs of Care}

The mean cost of the index hospitalisation was $€ 5318$. This cost rose slightly according to the number of previous hospitalisations for AECOPD, from $€ 5266$ for patients with no previous hospitalisations to $€ 5908$ in those with three or more previous hospitalisations (Table 3).

The mean specific cost of the first AECOPD rehospitalisation was $€ 5304$ (Table 3). The cost of this rehospitalisation for patients with at least one previous hospitalisation for AECOPD in the two years before the index hospitalisation ( $€ 5514)$ is $5.8 \%$ higher on average than for patients with no such previous hospitalisation ( $€ 5213)$ (Table 3).

The overall total cost per patient of all AECOPD-related stays was $€ 9623$ (Table 3). This cost was around twice as high in patients who were rehospitalised for an AECOPD in the 6-month following the index hospitalisation $(€ 16,275)$ than in those who were not ( $€ 8208)$. This overall cost also increased in function of the number of previous hospitalisations for AECOPD.

\section{Patient Profiles at Risk for AECOPD Rehospitalisation}

The decision tree analysis identified variables defining patient profiles at risk for rehospitalisation for AECOPD. Two iterations were performed. The first iteration was performed including all the variables listed in Table 1, which correspond to all the information available in the PMSI database at the time of the index stay. In this analysis, the number of previous hospitalisations for AECOPD was the most important driver of re-hospitalisation, contributing $85 \%$ of the information (Figure 4 ).

This first step demonstrated the importance of the number of previous rehospitalisations for AECOPD in the patient profile. Patients with at least one previous AECOPD hospitalisation ( $\mathrm{N}=21,606 ; 16 \%)$ were 2.2 [95\% CI 2.2-2.3] times more likely to be rehospitalised for AECOPD than patients with no AECOPD antecedent within the two years preceding the inclusion (Figure 5). On the other hand, patients with no previous AECOPD, aged $\leq 57$ years and without any of the nine comorbidities ( $\mathrm{N}=5300$ patients; $4 \%$ ) were $1.9[95 \% \mathrm{CI}$

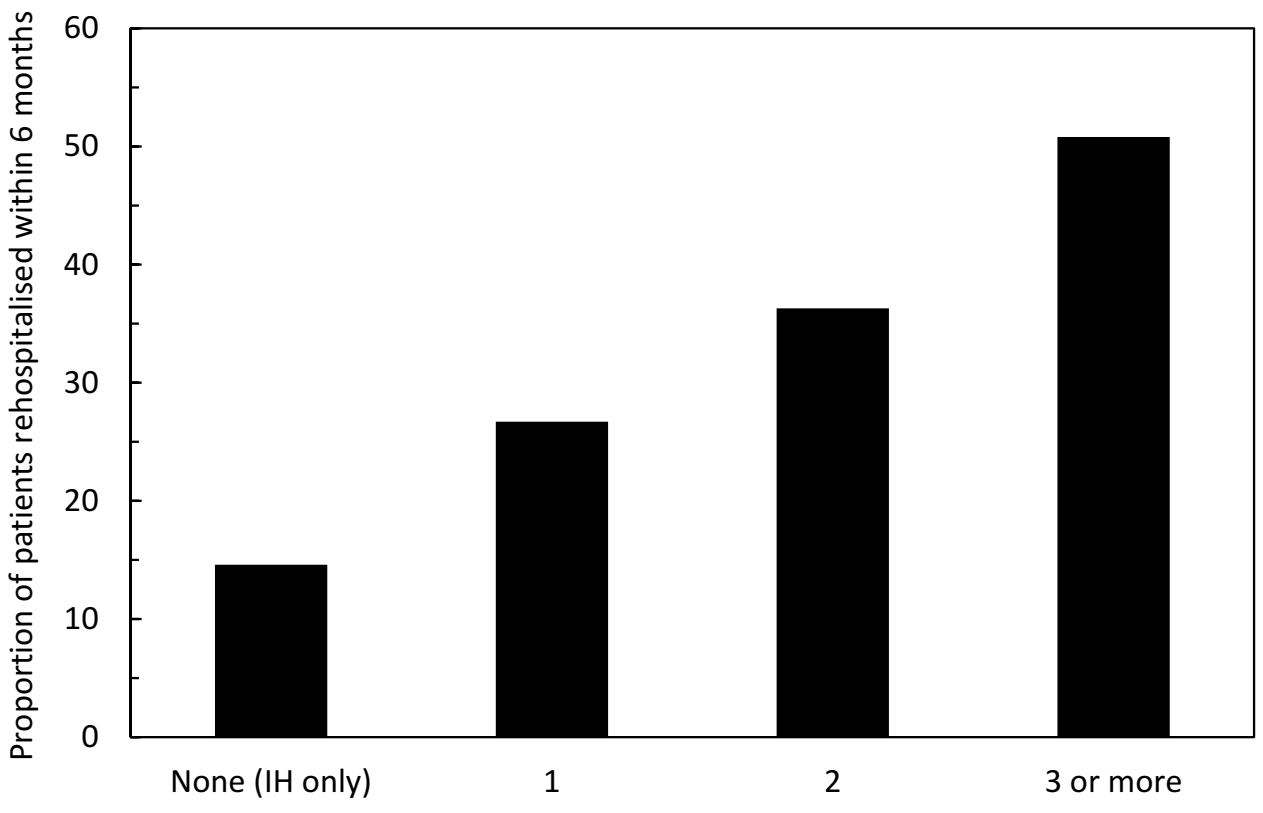

Number of previous hospitalisations for AECOPD

Figure 3 Rate of rehospitalisation for AECOPD as a function of the number of prior hospitalisations for AECOPD. Abbreviations: AECOPD, acute exacerbations of chronic obstructive pulmonary disease; $\mathrm{IH}$, index hospitalization. 
Table 3 Overall Cost of AECOPD-Related Stays

\begin{tabular}{|c|c|c|c|c|c|c|}
\hline \multirow[t]{2}{*}{ Population } & & \multirow[t]{2}{*}{$\mathbf{N}$} & \multirow{2}{*}{$\begin{array}{l}\text { Number of } \\
\text { REHOSP } \\
\text { (Mean } \pm \text { SD) }\end{array}$} & \multicolumn{3}{|c|}{ Mean Cost per Patient } \\
\hline & & & & $\begin{array}{l}\text { Index } \\
\text { Hospitalisation }\end{array}$ & $\begin{array}{l}\text { First } \\
\text { REHOSP }\end{array}$ & $\begin{array}{l}\text { Overall* } \\
\text { (6 Months) }\end{array}$ \\
\hline Overall cohort & & 143,006 & $1.35 \pm 0.72$ & $€ 5318$ & & $€ 9623$ \\
\hline $\begin{array}{l}\text { Number of times the patient was hospitalised for } \\
\text { AECOPD in the two years preceding the index } \\
\text { hospitalisation? }\end{array}$ & $\begin{array}{l}0 \\
1 \\
2 \\
\geq 3 \\
\geq 1\end{array}$ & $\begin{array}{l}119,776 \\
14,773 \\
4509 \\
3948 \\
23,230\end{array}$ & $\begin{array}{l}1.28 \pm 0.63 \\
1.37 \pm 0.72 \\
1.49 \pm 0.86 \\
1.79 \pm 1.11 \\
1.46 \pm 0.81\end{array}$ & $\begin{array}{l}€ 5266 \\
€ 5487 \\
€ 5607 \\
€ 5908 \\
€ 5582\end{array}$ & $\begin{array}{l}€ 5213 \\
€ 5550 \\
€ 5454 \\
€ 5494 \\
€ 5514\end{array}$ & $\begin{array}{l}€ 9250 \\
€ 10,581 \\
€ \quad 11,939 \\
€ 14,7 \mid 4 \\
€ 11,547\end{array}$ \\
\hline $\begin{array}{l}\text { Rehospitalisation for AECOPD in the six months } \\
\text { following the index hospitalisation? }\end{array}$ & $\begin{array}{l}\text { Yes } \\
\text { No }\end{array}$ & $\begin{array}{l}25,090 \\
117,916\end{array}$ & - & $\begin{array}{l}€ 5158 \\
€ 5352\end{array}$ & $€ 5304$ & $\begin{array}{l}€ 16,275 \\
€ 8208\end{array}$ \\
\hline
\end{tabular}

Note: *For this variable, all AECOPD-related costs were included.

Abbreviations: AECOPD, acute exacerbations of chronic obstructive pulmonary disease; REHOSP, rehospitalisation.

1.8-2.1] less likely to be rehospitalised for AECOPD than patients not in this group.

In the second iteration, information on previous rehospitalisations was omitted from the model. The rationale for this was to exclude the dominant driver (rehospitalisation for AECOPD in the previous two years) from the analysis, in order to discriminate the other drivers with greater sensitivity. To this end, each comorbidity was entered as a binary variable in the model, rather than as the number of comorbidities as a continuous variable, as in the first iteration. In this iteration, the most important drivers for AECOPD rehospitalisation were age, gender, nutritional disorders, duration of the index stay, anxiety and cardiovascular diseases.

In terms of patient profile the second analysis showed that, irrespective of the number of previous rehospitalisations for AECOPD, men aged $\geq 58$ years with anxiety $(\mathrm{N}=4321$; $3 \%)$ were 1.4 [95\% CI 1.3-1.5] times more likely to be rehospitalised for AECOPD than the other patients of the cohort (Figure 5). In contrast, women aged $\geq 58$ years with none of the nine comorbidities, whose index stay lasted less than five days $(\mathrm{N}=3054 ; 2 \%)$ were 1.7 [95\% CI 1.5-1.8] times less likely to be rehospitalised for AECOPD than the other patients of the cohort.

\section{Discussion}

This report describes patients with COPD who were rehospitalised for AECOPD. These patients present a major epidemiological and economic burden, since one in two patients in France hospitalised for an AECOPD were rehospitalised within six months for whatever reason and one in six were rehospitalised for an AECOPD. A novel machine learning approach was used to identify variables associated with rehospitalisation for AECOPD. The most discriminating variable associated with rehospitalisation was previous hospitalisation for AECOPD in the previous two years. This finding is consistent with those of several previous studies which have used multivariate logistic regression analysis to identify variables associated with rehospitalisation for

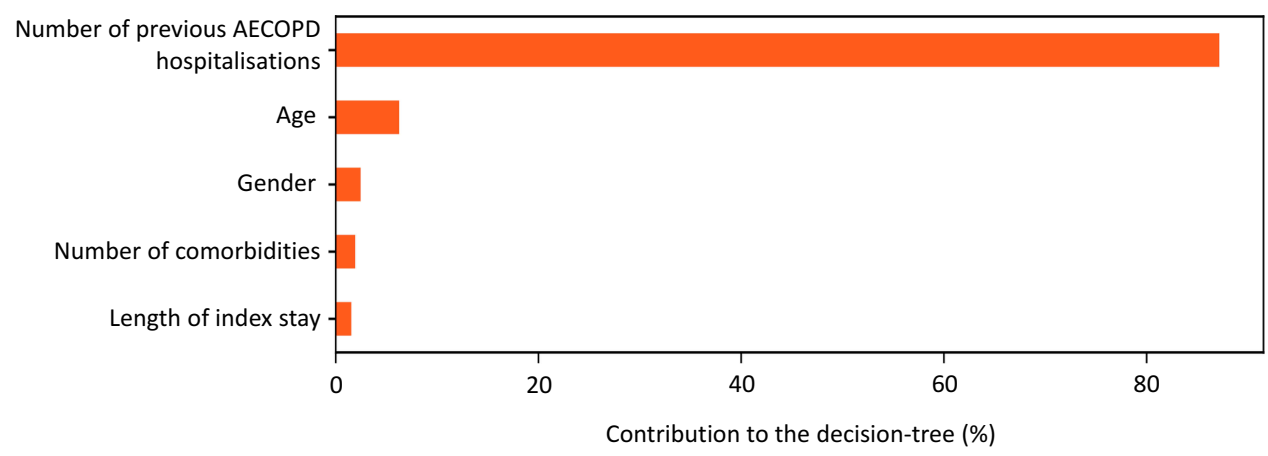

Figure 4 Relative contribution of variables associated with rehospitalisation for AECOPD. Abbreviation: AECOPD, acute exacerbations of chronic obstructive pulmonary disease. 


\section{Iteration 1}

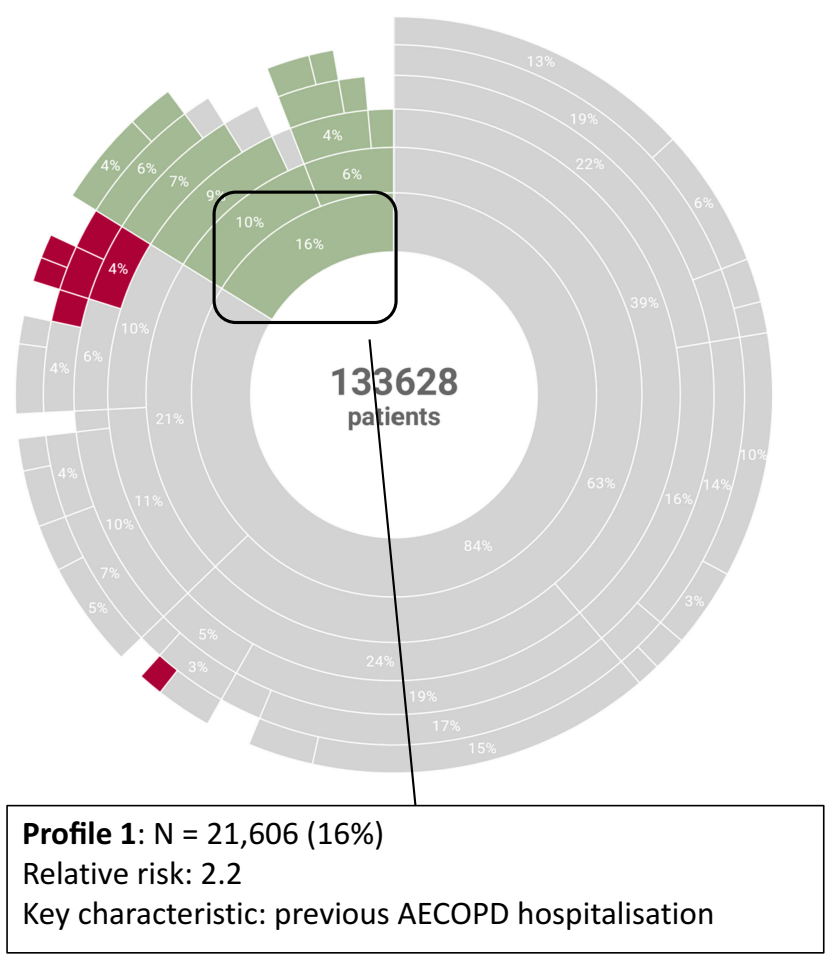

\section{Iteration 2}

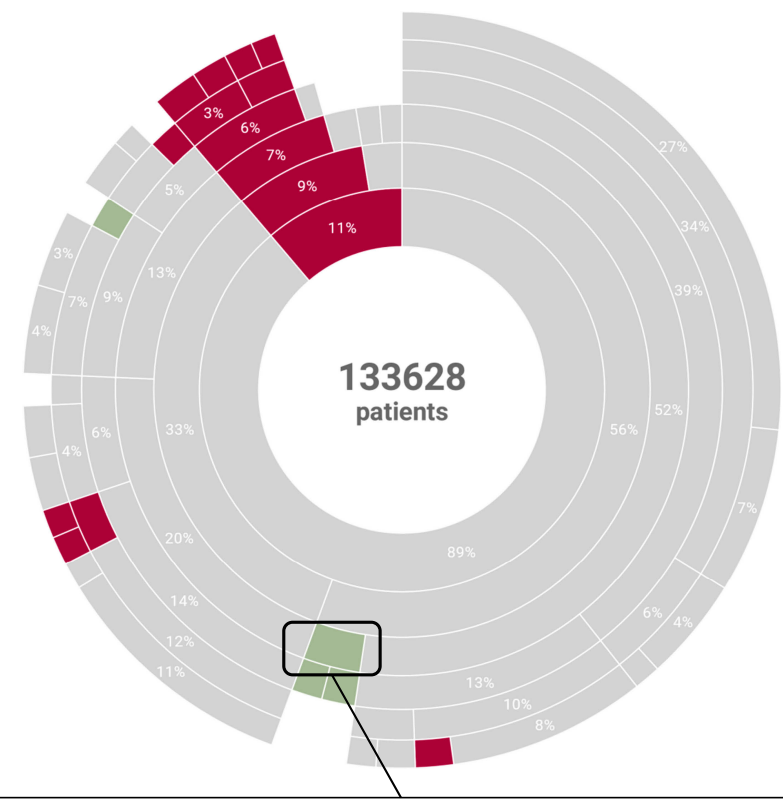

Profile 2: $\mathrm{N}=4,321$ (3\%)

Relative risk: 1.4

Key characteristics: men, age $\geq 58$ years, anxiety

Figure 5 Patient profiles associated with AECOPD rehospitalisation. Data are represented as sunburst plots. The analysis was performed to segregate the 25,090 patients with at least one rehospitalisation for AECOPD (green segments) and the remaining 108,538 patients who were not rehospitalised for AECOPD (purple segments). The grey segments correspond to segments where the purity score is too low to categorize patients with certainty (either rehospitalised or not). Left: decision tree analysis including AECOPD previous hospitalisation as a source variable; right: decision tree analysis excluding AECOPD previous hospitalisation.

Abbreviation: AECOPD, acute exacerbations of chronic obstructive pulmonary disease

AECOPD, thus supporting the external validity of the machine learning approach. ${ }^{12,13,15}$ The explanation for this association may be that individual exacerbations lead to accelerated lung function decline, thus increasing the risk of future exacerbations. ${ }^{26,27}$

The other important discriminating variable of rehospitalisation was the presence of comorbidities, both with respect to the number of these, and to their nature. Individual comorbidities associated with rehospitalisation were anxiety, nutritional disorders and cardiovascular diseases. This is partially consistent with previous findings from the ECLIPSE study, in which anxiety, gastroesophageal reflux disorder and depression but not diabetes and cardiovascular disorders were associated with the frequency of exacerbations. ${ }^{28}$ The relationship between the number of comorbidities and the probability of rehospitalisation has also been reported in a recent study of a Californian hospital admissions database. ${ }^{29}$ Similarly, an association between the presence of comorbidities in general and an increased risk of exacerbations has been reported previously. ${ }^{30}$ Malnutrition is a characterised consequence of COPD and increases with the severity of COPD. ${ }^{31}$ Since, in the GOLD severity classification, ${ }^{1}$ a history of frequent hospitalisations for AECOPD is a criterion for severity, the association between AECOPD and nutritional disorders observed in our study may be expected. Similarly, anxiety may be a consequence of COPD and may reflect fear and apprehension about experiencing a further exacerbation and its consequences. ${ }^{32}$ It is also plausible that anxious patients are more likely to seek medical help when they perceive and have symptoms of dyspnoea, leading to a higher hospitalisation rate. ${ }^{33}$ Associations between comorbid anxiety and depression on the one hand and rehospitalisation and mortality on the other, have been described in a previous study in a large American cohort. ${ }^{34}$ With respect to cardiovascular disease, the association between this and COPD is well documented, and may be explained by shared risk factors, notably smoking, and common underlying pathological mechanisms. ${ }^{31,35}$ The presence of comorbid cardiovascular disease is associated with more frequent $^{36}$ or longer ${ }^{37}$ hospitalisations for AECOPD. It is also possible that patients with cardiovascular disease are more fragile and thus more like to be hospitalised when they have an AECOPD than patient without comorbidities who present a similar level of dyspnoea. It should be noted 
that the choice of comorbidities analysed in this study was a subjective one, and other choices could have been made, such as including chronic kidney disease. ${ }^{38}$ Other medical conditions which are generally clinically silent and are not expected to influence the cost or course of hospitalisation are not recorded systematically in discharge summaries in the PMSI database. For this reason, such conditions, such as sarcopenia, ${ }^{39}$ even though known to be associated with COPD, have not been evaluated in this study.

Other variables associated with rehospitalisation were older age, male gender, and longer duration of the initial hospitalisation. The association with age is intuitive and may suggest that older patients are more fragile and thus more likely to be hospitalised. Men may be more at risk of rehospitalisation since they are heavier smokers and may this have more advanced COPD. Women also tend to be more receptive to healthcare advice and more adherent to medication, which may reduce the risk of rehospitalisation. Length of the index stay is likely to be associated with patients who are difficult to manage, and thus disease severity.

This study also demonstrated the high economic burden associated with AECOPD. Around half the study population were rehospitalised within six months of the index population, for another AECOPD in 18\% of cases. The risk of rehospitalisation increased linearly with the number of previous hospitalisation for AECOPD, as has also been reported in the North American setting. ${ }^{40}$ In our study, rehospitalisations for AECOPD were associated with higher mortality and higher management costs. In patients who were rehospitalised, the 6-month overall total cost per patient was $>€ 16,000$. The total cost to the French national health insurance of hospitalisations for AECOPD has been estimated to be $€ 670$ million, which is comparable to the cost of hospitalisations for acute heart failure. ${ }^{41}$ A recent retrospective survey of hospitalisation costs of COPD since 2007 has indicated that both the number of these hospitalisations and their cost have risen over this period. ${ }^{42}$

The advantage of the decision tree approach used in this study is that it allows relationships between variables to be identified in large data sets without a priori hypotheses and using all available data, and that the patient profiles identified are easily to apprehend. The principal limitations are that the quality of the output is dependent on the quality and pertinence of the input variables. In addition, as with all machine-learning approaches, output may be sensitive to small variations in the input variables and, for this reason, it would be important to replicate the findings on another dataset. Nonetheless, the patient profiles identified have good face validity and are consistent with what is known of variables associated with AECOPD from other types of analyses.

The PMSI database offers the advantage of being exhaustive, covering all hospitalisations in France, and of using standardised coding conventions to enable event rates and costs to be determined with confidence. The principal limitation is that certain pertinent variables are not documented, or incompletely documented, in the database. In the case of COPD, there is no information on spirometry or on COPD severity, other than the fact that hospitalisation for AECOPD enters into the GOLD classification of COPD severity. ${ }^{1}$ Importantly, there is no information on prescription of controller medication or an adherence, which is an important determinant of COPD control and thus on the probability of readmission. ${ }^{43}$ In addition, information on comorbidities may be incomplete, if not considered sufficiently important to be listed on the standardised discharge summary, as will be information on procedures that may be provided in the community as well as in hospital, such as RR and RFE. To overcome such limitations, it would be of interest to reiterate the analysis using the SNDS (Système National des Données de Santé) database, which includes comprehensive data on all healthcare provision in France, including medication prescription and community care, and which has recently become available for researchers. This would enable the impact of respiratory rehabilitation in the community, as well as the use of controller medication, two variables that have been demonstrated consistently to be associated with a reduced risk of hospitalisation for AECOPD, ${ }^{4-46}$ to be integrated into the decision tree analysis. Finally, coding errors may limit the reliability of diagnostic assignment from the discharge summaries in the PMSI. However, the quality and exhaustiveness of data coding compared to patient registries in other fields, notably cancer, has been shown to be high. ${ }^{47}$ Although no such study has been performed for COPD, the algorithm used for case identification in this study, which was developed over ten years ago by the InVS, has been shown to reproduce faithfully changes in hospitalisation rates for COPD identified from other sources. $^{23}$

The findings of our study reinforce the message of earlier ones regarding the importance of adequate and systematic follow-up of patients following a hospitalisation for AECOPD. As advocated in the GOLD recommendations ${ }^{1}$ 
and in international ${ }^{48}$ and French ${ }^{49,50}$ practice guidelines, this follow-up could include regular symptom monitoring, reduction in exposure to risk factors, adapting controller medication if necessary and reinforcing messages about adherence.

\section{Conclusion}

This study confirms the high epidemiological and economic burden of the hospitalisations for AECOPD in France, with nearly one in five patients being rehospitalised for an AECOPD within six months. Since hospitalisation for AECOPD is the most important determinant of future rehospitalisation, management of COPD needs to focus on interventions and educational programmes aimed at decreasing the risk of rehospitalisation, in order to lower the burden of disease associated with exacerbations of COPD.

\section{Data Sharing Statement}

The analysis described in this manuscript was performed in a national database (Programme de Médicalisation des Systèmes d'Information; PMSI) belonging to a third-party, namely the French Ministry of Health. Access to this database is freely available to researchers on reasonable demand, upon request to the relevant agency, the Institut National des Données de Santé (INDS), 19 rue Arthur Croquette, 94220 Charenton-le-Pont, Telephone: +33145 1843 90; email: contact@indsante.fr; Website: https:// www.indsante.fr/fr, on condition that the analyses envisaged have been authorised by the French Data Protection Agency (Commission nationale de l'Informatique et des Libertés, 3 Place de Fontenoy, 75007 Paris).

\section{Author Contributions}

The study was initiated by KLL, DC, LL and PLL. AC, BM, GB and TF were members of the Steering Committee which oversaw the implementation of the study. Data extraction and analyses were performed by FD, ML and SM. All authors made substantial contributions to conception and design, acquisition of data, or analysis and interpretation of data: KLL, DC, LL and PLL closely worked with AC, BM, GB and TF to design the algorithm for case extraction and to identify relevant medical outcomes of the study; FD, ML and SM designed the statistical analysis plan in accordance. All eleven authors contributed to the interpretation of the study and to the decision to publish the results. Preparation of the study manuscript was coordinated by ML and the writing was shared and revised among authors based on their field. All authors were involved in drafting the article or revising it critically for important intellectual content and gave final approval of the version to be published. All authors agree to be accountable for all aspects of the work in ensuring that questions related to the accuracy or integrity of any part of the work are appropriately investigated and resolved.

\section{Funding}

The study was funded by Boehringer Ingelheim SA.

\section{Disclosure}

AC reports no conflict of interest regarding this present study. Outside the submitted work, he has received personal fees or non-financial support from GSK France, Boehringer Ingelheim France, Chiesi France and Novartis France. BM reports no conflict of interest regarding this present study. Outside the submitted work, he has received personal fees and/or non-financial support from AstraZeneca France, Boehringer Ingelheim France, Chiesi France, Menarini France, Roche, Glaxo Smith Kline, and Novartis France. ML reports grants from Boehringer Ingelheim during the conduct of the study. SM, FD and ML are employees of HEVA, a company who received funding from the study sponsor for the conduct of this study. KLL, DC, LL and PLL are employees of Boehringer Ingelheim SA, who funded the study and market medications for the treatment of COPD. GB has nothing to disclose. Regarding this present study, $\mathrm{TF}$ reports that he has received personal fees from Boehringer Ingelheim France.

\section{References}

1. Global Initiative for Chronic Obstructive Lung Disease G. Global strategy for the diagnosis, management and prevention of chronic obstructive pulmonary disease. Updated 2013; 2019.

2. Lozano R, Naghavi M, Foreman K, et al. Global and regional mortality from 235 causes of death for 20 age groups in 1990 and 2010: a systematic analysis for the Global Burden of Disease Study 2010. Lancet. 2012;380(9859):2095-2128. doi:10.1016/S0140-6736(12) 61728-0

3. Mathers CD, Loncar D. Projections of global mortality and burden of disease from 2002 to 2030. PLoS Med. 2006;3(11):e442. doi:10.1371/ journal.pmed.0030442

4. Roche N, Dalmay F, Perez T, et al. Impact of chronic airflow obstruction in a working population. Eur Respir J. 2008;31(6):1227-1233. doi:10.1183/09031936.00089607

5. Piperno D, Huchon G, Pribil C, Boucot I, Similowski T. The burden of COPD in France: results from the confronting COPD survey. Respir Med. 2003;97 Suppl C:S33-42. doi:10.1016/S0954-6111(03)80023-9

6. Huchon GJ, Vergnenegre A, Neukirch F, Brami G, Roche N, Preux PM. Chronic bronchitis among French adults: high prevalence and underdiagnosis. Eur Respir J. 2002;20(4):806-812. doi:10.1183/ 09031936.02.00042002 
7. Fuhrman C, Delmas M-C. Épidémiologie descriptive de la bronchopneumopathie chronique obstructive (BPCO) en France. [Descriptive epidemiology of Chronic Obstructive Pulmonary Disease (COPD) in France]. Rev Malad Respir. 2010;27(2):160-168. doi:10.1016/j.rmr.2009.08.003 [In French].

8. Laurendeau C, Chouaid C, Roche N, Terrioux P, Gourmelen J, Detournay B. Prise en charge et coûts de la bronchopneumopathie chronique obstructive en France en 2011. [Management and costs of chronic pulmonary obstructive disease in France in 2011]. Rev Mal Respir. 2015;32(7):682-691. doi:10.1016/j.rmr.2014.10.731 [In French].

9. Soler-Cataluna JJ, Martinez-Garcia MA, Roman Sanchez P, Salcedo E, Navarro M, Ochando R. Severe acute exacerbations and mortality in patients with chronic obstructive pulmonary disease. Thorax. 2005;60(11):925-931. doi:10.1136/thx.2005.040527

10. Perera PN, Armstrong EP, Sherrill DL, Skrepnek GH. Acute exacerbations of COPD in the United States: inpatient burden and predictors of costs and mortality. Copd. 2012;9(2):131-141. doi:10.3109/ 15412555.2011.650239

11. Fournier M, Tonnel AB, Housset B, et al. Impact économique de la BPCO en France: étude SCOPE. [Economic impact of COPD in France: SCOPE study]. Rev Mal Respir. 2005;22(2 Pt 1):247-255. doi:10.1016/S0761-8425(05)85478-6 [In French].

12. Hurst JR, Vestbo J, Anzueto A, et al. Susceptibility to exacerbation in chronic obstructive pulmonary disease. $N$ Engl J Med. 2010;363 (12):1128-1138. doi:10.1056/NEJMoa0909883

13. Mullerova H, Maselli DJ, Locantore N, et al. Hospitalized exacerbations of COPD: risk factors and outcomes in the ECLIPSE cohort. Chest. 2015;147(4):999-1007. doi:10.1378/chest.14-0655

14. Han MK, Kazerooni EA, Lynch DA, et al. Chronic obstructive pulmonary disease exacerbations in the COPDGene study: associated radiologic phenotypes. Radiology. 2011;261(1):274-282. doi:10.1148/radiol.11110173

15. Han MK, Quibrera PM, Carretta EE, et al. Frequency of exacerbations in patients with chronic obstructive pulmonary disease: an analysis of the SPIROMICS cohort. Lancet Respir Med. 2017;5 (8):619-626. doi:10.1016/S2213-2600(17)30207-2

16. Mannino DM, Tal-Singer R, Lomas DA, et al. Plasma fibrinogen as a biomarker for mortality and hospitalized exacerbations in people with COPD. Chronic Obstr Pulm Dis. 2015;2(1):23-34. doi:10.15326/ jcopdf.2.1.2014.0138

17. Breiman L, Friedman J, Stone CJ, Olshen RA. Classification and Regression Trees. Belmont: Wadsworth International; 1984.

18. Rennard SI. The promise of observational studies (ECLIPSE, SPIROMICS, and COPDGene) in achieving the goal of personalized treatment of chronic obstructive pulmonary disease. Semin Respir Crit Care Med. 2015;36(4):478-490. doi:10.1055/s-00000075

19. Rennard SI, Locantore N, Delafont B, et al. Identification of five chronic obstructive pulmonary disease subgroups with different prognoses in the ECLIPSE cohort using cluster analysis. Ann Am Thorac Soc. 2015;12(3):303-312. doi:10.1513/AnnalsATS.201403-125OC

20. Koppad SH, Kumar A Application of big data analytics in healthcare system to predict COPD. International Conference on Circuit, Power and Computing Technologies [ICCPCT]; 2016; Nagercoil, India

21. Ministere des Solidarites et de la Santé. Guide methodologique de production des informations relatives a l'activite medicale et a sa facturation en medecine, chirurgie, obstetrique et odontologie. [Methodological guide for the production of information relating to medical activity and its invoicing in medicine, surgery, obstetrics and dentistry]. Bull Off. 2014. [In French].

22. Bezin J, Duong M, Lassalle R, et al. The national healthcare system claims databases in France, SNIIRAM and EGB: powerful tools for pharmacoepidemiology. Pharmacoepidemiol Drug Saf. 2017;26 (8):954-962. doi:10.1002/pds.v26.8

23. Fuhrman C, Delmas MC. Hospitalisations pour exacerbations de BPCO: Comment les identifier à partir des données du programme de médicalisation des systèmes d'information? [Hospitalizations for COPD exacerbations: How to identify them from the data of the information systems medicalization program?]. Saint-Maurice: Institut de veille sanitaire; 2009. [In French].
24. Rey G, Jougla E, Fouillet A, Hemon D. Ecological association between a deprivation index and mortality in France over the period 1997-2001: variations with spatial scale, degree of urbanicity, age, gender and cause of death. BMC Public Health. 2009;9:33. doi:10.1186/1471-2458-9-33

25. De Oliveira H, Prodel M, Augusto V Binary classification on French hospital data: benchmark of 7 machine learning algorithms. Paper presented at: IEEE International Conference on Systems, Man, and Cybernetics; 2018; Miyazaki, Japan.

26. Donaldson GC, Law M, Kowlessar B, et al. Impact of prolonged exacerbation recovery in chronic obstructive pulmonary disease. $\mathrm{Am}$ $J$ Respir Crit Care Med. 2015;192(8):943-950. doi:10.1164/ rccm.201412-2269OC

27. Donaldson GC, Seemungal TA, Bhowmik A, Wedzicha JA. Relationship between exacerbation frequency and lung function decline in chronic obstructive pulmonary disease. Thorax. 2002;57 (10):847-852. doi:10.1136/thorax.57.10.847

28. Donaldson GC, Mullerova H, Locantore N, et al. Factors associated with change in exacerbation frequency in COPD. Respir Res. 2013;14:79. doi:10.1186/1465-9921-14-79

29. Buhr RG, Jackson NJ, Kominski GF, Dubinett SM, Ong MK, Mangione CM. Comorbidity and thirty-day hospital readmission odds in chronic obstructive pulmonary disease: a comparison of the Charlson and Elixhauser comorbidity indices. BMC Health Serv Res. 2019;19(1):701. doi:10.1186/s12913-019-4549-4

30. Mahboub B, Alzaabi A, Iqbal MN, et al. Comorbidities associated with COPD in the Middle East and North Africa region: association with severity and exacerbations. Int J Chron Obstruct Pulmon Dis. 2016;11:273-280. doi:10.2147/COPD.S90626

31. Cavailles A, Brinchault-Rabin G, Dixmier A, et al. Comorbidities of COPD. Eur Respir Rev. 2013;22(130):454-475. doi:10.1183/09059 180.00008612

32. Gudmundsson G, Gislason T, Janson C, et al. Risk factors for rehospitalisation in COPD: role of health status, anxiety and depression. Eur Respir J. 2005;26(3):414-419. doi:10.1183/09031936.05.000 78504

33. Regvat J, Zmitek A, Vegnuti M, Kosnik M, Suskovic S. Anxiety and depression during hospital treatment of exacerbation of chronic obstructive pulmonary disease. J Int Med Res. 2011;39 (3):1028-1038. doi:10.1177/147323001103900338

34. Abrams TE, Vaughan-Sarrazin M, Van der Weg MW. Acute exacerbations of chronic obstructive pulmonary disease and the effect of existing psychiatric comorbidity on subsequent mortality. Psychosomatics. 2011;52 (5):441-449. doi:10.1016/j.psym.2011.03.005

35. Morgan AD, Zakeri R, Quint JK. Defining the relationship between COPD and CVD: what are the implications for clinical practice? Ther Adv Respir Dis. 2018;12:1753465817750524. doi:10.1177/175346 5817750524

36. Maclay JD, MacNee W. Assessment of cardiovascular comorbidity. In: Rabe KF, Wedzicha JA, Wouters EFM, editors. COPD and Comorbidity. Vol. Monograph 59. European Respiratory Society; 2013:28-49.

37. Patel ARC, Donaldson GC, Mackay AJ, Wedzicha JA, Hurst JR. The impact of ischemic heart disease on symptoms, health status, and exacerbations in patients with COPD. Chest. 2012;141(4):851-857. doi:10.1378/chest.11-0853

38. Blanchette CM, Berry SR, Lane SJ. Advances in chronic obstructive pulmonary disease among older adults. Curr Opin Pulm Med. 2011;17(2):84-89. doi:10.1097/MCP.0b013e32834316ff

39. Benz E, Trajanoska K, Lahousse L, et al. Sarcopenia in COPD: a systematic review and meta-analysis. Eur Respir Rev. 2019;28:154. doi:10.1183/16000617.0049-2019

40. Dhamane AD, Moretz C, Zhou Y, et al. COPD exacerbation frequency and its association with health care resource utilization and costs. Int J Chron Obstruct Pulmon Dis. 2015;10:2609-2618. doi: $10.2147 / \mathrm{COPD}$ 
41. Assurance Maladie. Améliorer la qualité du système de santé et maîtriser les dépenses. Propositions de l'Assurance Maladie pour 2019. [Improve the quality of the health system and control spending. Health Insurance proposals for 2019]. Paris: Caisse Nationale de l'Assurance Maladie; 2018. [In French].

42. Molinari N, Chanez P, Roche N, Ahmed E, Vachier I, Bourdin A. Rising total costs and mortality rates associated with admissions due to COPD exacerbations. Respir Res. 2016;17(1):149. doi:10.1186/ s12931-016-0469-6

43. Toy EL, Beaulieu NU, McHale JM, et al. Treatment of COPD: relationships between daily dosing frequency, adherence, resource use, and costs. Respir Med. 2011;105(3):435-441. doi:10.1016/j.rmed.2010.09.006

44. Puhan MA, Scharplatz M, Troosters T, Steurer J. Respiratory rehabilitation after acute exacerbation of COPD may reduce risk for readmission and mortality - a systematic review. Respir Res. 2005;6:54. doi:10.1186/1465-9921-6-54

45. van Boven JF, Chavannes NH, van der Molen T, Rutten-van Molken MP, Postma MJ, Vegter S. Clinical and economic impact of non-adherence in COPD: a systematic review. Respir Med. 2014;108 (1):103-113. doi:10.1016/j.rmed.2013.08.044
46. Halpin DM, Miravitlles M, Metzdorf N, Celli B. Impact and prevention of severe exacerbations of COPD: a review of the evidence. Int $J$ Chron Obstruct Pulmon Dis. 2017;12:2891-2908. doi:10.2147/COPD.S139470

47. Doat S, Samson S, Fagot-Campagna A, Tuppin P, Menegaux F. Estimation of breast, prostate, and colorectal cancer incidence using a French administrative database (general sample of health insurance beneficiaries). Rev Epidemiol Sante Publique. 2016;64(3):145-152. doi:10.1016/j.respe.2015.12.020

48. Wedzicha JAE-C-C, Miravitlles M, Hurst JR, et al. Management of COPD exacerbations: a European Respiratory Society/American Thoracic Society guideline. Eur Respir J. 2017;49(3):1600791. doi:10.1183/13993003.00791-2016

49. Jouneau S, Chabot F, Roche N. New guidelines for acute COPD exacerbations. Rev Mal Respir. 2017;34(4):279-281. doi:10.1016/j. rmr.2017.05.001

50. Haute Autorité de Santé. Bronchopneumopathie chronique obstructive. Guide du parcours de soins [Chronic obstructive pulmonary disease. Care pathway guidelines]. 2014. [In French].

\section{Publish your work in this journal}

The International Journal of COPD is an international, peer-reviewed journal of therapeutics and pharmacology focusing on concise rapid reporting of clinical studies and reviews in COPD. Special focus is given to the pathophysiological processes underlying the disease, intervention programs, patient focused education, and self management protocols. This journal is indexed on PubMed Central, MedLine and CAS. The manuscript management system is completely online and includes a very quick and fair peer-review system, which is all easy to use. Visit http://www.dovepress.com/testimonials.php to read real quotes from published authors. 